\title{
The Effect of Atomic Layer Deposition Temperature on Switching Properties of HfOx Resistive RAM Devices
}

\author{
Katrina A. Morgan, Ruomeng Huang, Stuart Pearce, C. H. De Groot \\ Nano Research Group \\ Electronics and Computer Science, University of Southampton \\ Southampton, SO171BJ, UK \\ kam2g11@ecs.soton.ac.uk
}

\begin{abstract}
TiN/HfOx/TiN resistive RAM (RRAM) devices have been fabricated where the hafnium oxide layer has been deposited at three different temperatures via atomic layer deposition (ALD). Material characterization shows the structure of the hafnium oxide is converted from cubic to monoclinic for 400 degrees $C$. Elemental analysis shows that the temperature affects the stoichiometric behavior of hafnium oxide, with a higher oxygen concentration at 350 degrees $C$ and above. The switching behavior differs significantly for each device whereby the 400 degrees $C$ device shows no successful switching, due to the change in structure to monoclinic. The two lower temperatures both show successful bipolar switching which set at negative voltages. The 300 degrees $C$ device has a higher Roff/Ron of 13.9, with superior endurance. The 350 degrees $C$ device has a lower Roff/Ron of 5.5 and shows deterioration in switching properties as the number of cycles are increased. At 300 degrees $C$, the oxygen hafnium ratio is at a minimum; hence the greatest amount of oxygen vacancies are present, which results in improved switching characteristics. This supports the theory that oxygen vacancies play a key role in the switching mechanism for metal oxide RRAM devices.
\end{abstract}

Keywords- oxygen concentraiton; Resistive RAM; hafnium oxide; switching mechanism

\section{INTRODUCTION}

Resistive RAM has the potential to become a new type of non-volatile memory, where its advantageous properties include high speed, high density memory with simple structures [1]. The switching mechanism behind this new type of memory however is still not fully understood although for metal oxide devices, oxygen vacancies are thought to play a key role [2].

Many papers have investigated the role of the electrode and insulator material types, where particular attention has been paid to the interfacial layers that form between these layers [35]. Other papers have also investigated the role of oxygen ions within the insulator materials, varying the amount of oxygen that is input into the chamber during deposition [6-8]. It has been seen that when oxygen vacancies are increased, the switching properties improve $[5,9,10]$.

For $\mathrm{HfO}_{\mathrm{x}}$, atomic layer deposition (ALD) is often the tool of choice due to the self-limiting growth regime allowing a uniform, stoichiometric and well controlled layer to be deposited [11-12]. When trying to alter the oxygen concentration however, an increase in oxygen flow rate does not necessarily result in an increase in oxygen due to the selflimiting growth reaction. Papers have instead reported the oxygen concentration is effected when the temperature of the sample holder is altered [13-14]. The purpose of these papers is to grow stoichiometric layers and does not include effects on device characteristics. This work will investigate how this temperature will affect the switching properties of the RRAM device. TiN/ $/ \mathrm{HfO}_{\mathrm{x}} / \mathrm{TiN}$ devices have been fabricated where the table temperatures for ALD are $300^{\circ} \mathrm{C}, 350^{\circ} \mathrm{C}$ and $400^{\circ} \mathrm{C}$. The fabrication of the devices is explained in section 2 , followed by the material characterization in section 3. Section 4 discusses the I-V electrical characteristics of the RRAM devices. Finally, section 5 concludes this paper.

\section{DEVICE FABRICATION}

$\mathrm{TiN} / \mathrm{HfO}_{\mathrm{x}} / \mathrm{TiN}$ devices were fabricated where the temperature of the $\mathrm{HfO}_{\mathrm{x}}$ layer was varied. To fabricate the devices, silicon dioxide was reactively sputtered onto silicon wafers, providing electrical isolation between the device and wafer below, using a Leybold Optics Helios Pro XL. Following this, the bottom TiN electrode was reactively sputtered using a titanium target in nitrogen ambient. Silicon dioxide was again sputtered, followed by a photolithography and dry etching stage, creating the devices and access to the bottom electrode. Fig. 1 depicts the device structure, whereby the device area ranges from $1 \mu \mathrm{m}^{2}$ to $100 \mu \mathrm{m}^{2}$.

The hafnium oxide was then deposited via atomic layer deposition using an OIPT Flex ALD Tool DP03, with TEMAH and $\mathrm{O}_{2}$ as the precursors. A dose time of $0.8 \mathrm{~s}$ was used for 50 cycles. Three table deposition temperatures were selected; $300^{\circ} \mathrm{C}, 350^{\circ} \mathrm{C}$ and $400^{\circ} \mathrm{C}$. After the material characterization, discussed in section 3, the top TiN electrode was deposited, followed by patterning with photolithography and dry etching.

\section{MATERIAL CHARACTERISATION}

The material characterization for the $\mathrm{HfO}_{\mathrm{x}}$ layer was conducted using X-ray diffraction (XRD), scanning electron 


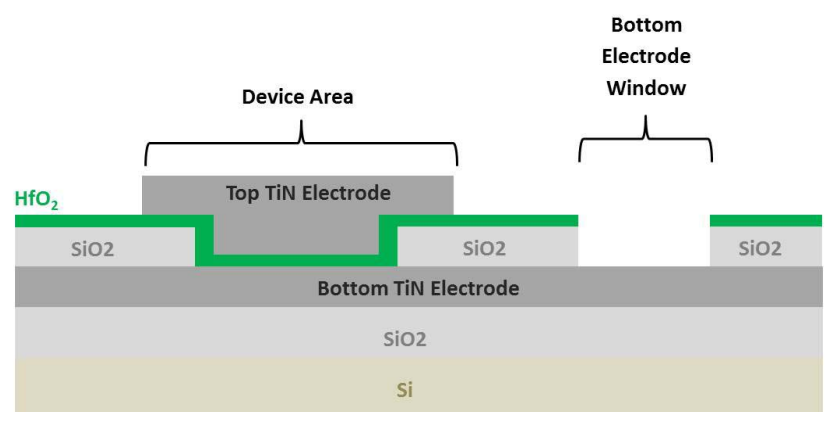

Fig. 1. Graphical representation of $\mathrm{TiN} / \mathrm{HfO}_{\mathrm{x}} / \mathrm{TiN}$ device structure where area of devices range from $1 \mu \mathrm{m}^{2}$ to $100 \mu \mathrm{m}^{2}$.

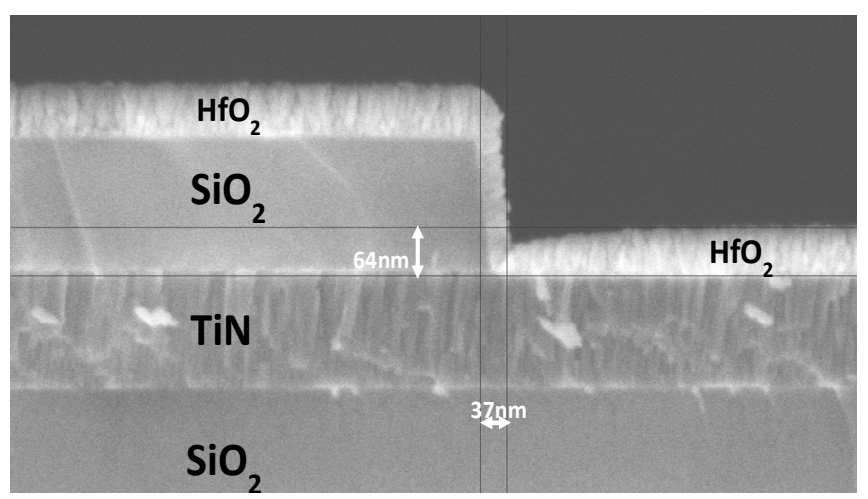

Fig. 2. SEM image of device structure prior to top electrode deposition, where $\mathrm{HfO}_{\mathrm{x}}$ is deposited at $400^{\circ} \mathrm{C}$. Thickness of hafnium oxide layer on device bottom is $64 \mathrm{~nm}$, where sidewall coverage is $37 \mathrm{~nm}$.

microscopy (SEM), and X-ray photoelectron spectroscopy (XPS).

\section{A. SEM images showing thickness variation of $\mathrm{HfO}_{x}$ films}

In order to measure the thickness of the hafnium oxide layer deposited, each device's cross section was measured using an SEM, before the top electrode was deposited. Fig. 2 shows a cross section of the device whose $\mathrm{HfO}_{\mathrm{x}}$ was deposited at $400^{\circ} \mathrm{C}$. The layers of each material can be seen clearly, along with the thickness of the hafnium oxide layer. Please note the $\mathrm{HfO}_{\mathrm{x}}$ sidewall is thinner than the bottom; however this is the same for all the devices and will have little impact. It was noted that the thickness of the $\mathrm{HfO}_{\mathrm{x}}$ layers varied with deposition temperature, where Table I shows the thickness of the $\mathrm{HfO}_{\mathrm{x}}$ on the bottom of the device opening.

The variation in thickness can be attributed to the temperature variation, whereby ALD results in a self-limited chemical reaction which is heavily effected by many parameters, including temperature. This complex reaction will alter for each parameter change, resulting in variations in thickness, atomic concentration and structure.

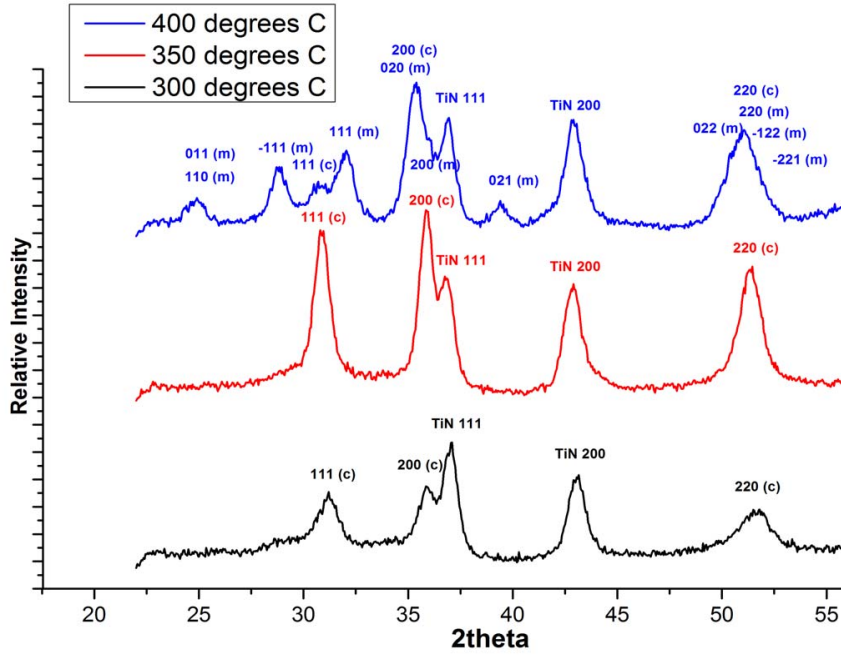

Fig. 3. XRD pattern for three deposition temperatures of $\mathrm{HfO}_{\mathrm{x}}$ whereby $400^{\circ} \mathrm{C}$ device (top) is shown to be monoclinic and the remaining devices are cubic

TABLE I. $\quad \mathrm{HFO}_{\mathrm{x}}$ THICKNESSES FOR VARIED DEPOSITION TEMPEERATURES

\begin{tabular}{|l|c|c|c|}
\hline ALD Deposition Temperature $\left({ }^{\circ} \mathrm{C}\right)$ & 300 & 350 & 400 \\
\hline Thickness at bottom electrode $(\mathrm{nm})$ & 48 & 55 & 63 \\
\hline
\end{tabular}

\section{B. XRD of $H f O_{x}$ films}

The crystal structure of each device was measured using XRD where patterns were collected in grazing incidence $\left(\Theta 1=3^{\circ}\right)$ using a Bruker D8 with GADDS diffractometer $(\mathrm{Cu}-$ $\mathrm{K} \alpha_{1}$ ) for phase identification purposes. The XRD patterns for each device are shown in Fig. 3 where the peaks have been identified as cubic $\mathrm{HfO}_{\mathrm{x}}$, labeled as (c), monoclinic $\mathrm{HfO}_{\mathrm{x}}$ labeled as $(\mathrm{m})$ or TiN. The TiN is present due to the $\mathrm{HfO}_{\mathrm{x}}$ being situated on top of the bottom electrode. The $300^{\circ} \mathrm{C}$ and $350^{\circ} \mathrm{C}$ devices have a similar cubic $\mathrm{HfO}_{\mathrm{x}}$ structure. A clear structural change is evident for the $400^{\circ} \mathrm{C}$ device where monoclinic $\mathrm{HfO}_{\mathrm{x}}$ peaks are identified.

\section{XPS of $\mathrm{HfO}_{x}$ films}

XPS was conducted on all three devices, before the top electrode was deposited allowing the $\mathrm{HfO}_{\mathrm{x}}$ to be analyzed, using a Thermo Scientific Theta Probe XPS system. Hf4f, O1s and $\mathrm{C} 1 \mathrm{~s}$ peak energies were measured eight times, where an argon etch was performed between the measurements, allowing for surface contamination to be reduced. The results are shown in Fig. 4 whereby the dashed lines show the atomic concentration of the oxygen and the solid lines show hafnium. Please note the carbon detected was negligible and therefore disregarded in atomic concentration calculations by the 


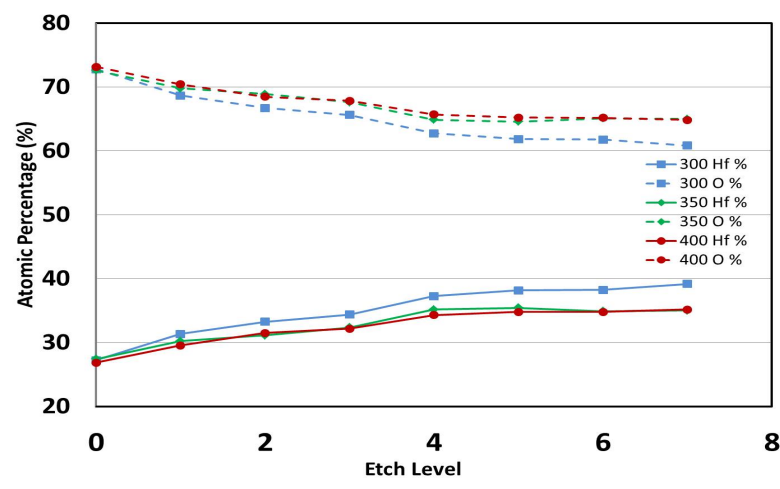

Fig. 4. XPS results showing atomic concentration of hafnium and oxygen found in three $\mathrm{HfO}_{\mathrm{x}}$ layers, deposited varied temperatures. $300^{\circ} \mathrm{C}$ can be seen to have a lower oxygen concentration when compared to higher temperatures

TABLE II. X RATIO VALUES FOR $\mathrm{HFO}_{x}$ AT VARIED DEPOSITION TEMPERATURES

\begin{tabular}{|l|c|c|c|}
\hline ALD Deposition Temperature $\left({ }^{\circ} \mathrm{C}\right)$ & $\mathbf{3 0 0}$ & $\mathbf{3 5 0}$ & $\mathbf{4 0 0}$ \\
\hline Hf:O - (x value of $\left.\mathrm{HfO}_{\mathbf{x}}\right)$ & 1.68 & 1.85 & 1.92 \\
\hline
\end{tabular}

TABLE III. SWITCHING PROPERTIES FOR 300 AND $350^{\circ} \mathrm{C}$ HFO $_{\mathrm{X}}$ DEVICES

\begin{tabular}{|l|c|c|}
\hline ALD Deposition Temperature $\left({ }^{\circ} \mathbf{C}\right)$ & 300 & 350 \\
\hline AVERAGE $\mathbf{R}_{\text {ON }}(\mathbf{\Omega})$ & $2.1 \mathrm{k}$ & $3.5 \mathrm{k}$ \\
\hline AVERAGE $\mathbf{R}_{\text {OFF }}(\mathbf{\Omega})$ & $27.0 \mathrm{k}$ & $14.7 \mathrm{k}$ \\
\hline AVERAGE $\mathbf{R}_{\text {OFF }} / \mathbf{R}_{\text {ON }}$ & 13.9 & 5.5 \\
\hline
\end{tabular}

Avantage software. The results show that all devices are substoichiometric. The $300^{\circ} \mathrm{C}$ can be seen to have the lowest oxygen concentration which is displayed in Table II, where the ratio of the hafnium to oxide concentration values can be seen.

\section{ELECTRICAL CHARACTERISATION}

Preliminary characterization was performed on each device after the top electrode was deposited. I-V sweeps were conducted using an Agilent B1500 semiconductor analyzer system on a prober bench. All devices were found to be bipolar, where forming and set steps occurred in negative voltages and reset steps occurred when positive voltage was applied to the top electrode. Table III shows the resistance values for the on and off state along with the ratio for the $300^{\circ} \mathrm{C}$ and $350^{\circ} \mathrm{C}$ devices. Please note these values are average values taken from at least eight IV sweeps per device, over at least three devices for each temperature.

\section{A. $H f O_{x}$ deposition at $300^{\circ} \mathrm{C}$}

Fig. 5 Shows the I-V sweeps for an $8 \mu \mathrm{m}^{2}$ sized device where the $\mathrm{HfO}_{\mathrm{x}}$ was deposited at $300^{\circ} \mathrm{C}$. The I-V graphs show repeated sweeps, whereby the direction of sweep is shown with black arrows. The order of the sweeps is shown in the legend

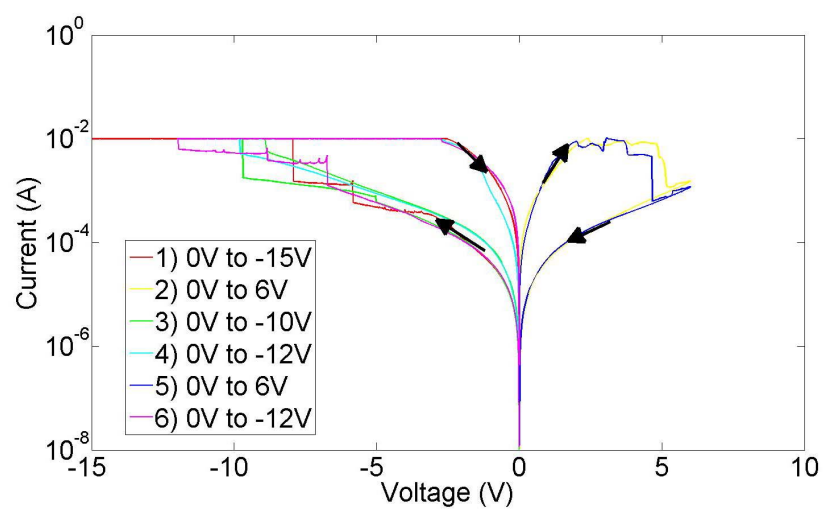

Fig. 5. IV sweeps of an $8 \mu \mathrm{m}^{2} \mathrm{HfO}_{\mathrm{x}}$ device at $300^{\circ} \mathrm{C}$ where average switching parameters are: forming voltage $=-18 \mathrm{~V}$, reset voltage $=4 \mathrm{~V}$, set voltage $=$ $10 \mathrm{~V}$, Ron $=3.2 \mathrm{k} \Omega$, Roff $=39.4 \mathrm{k} \Omega$, Roff $/$ Ron $=12.4$

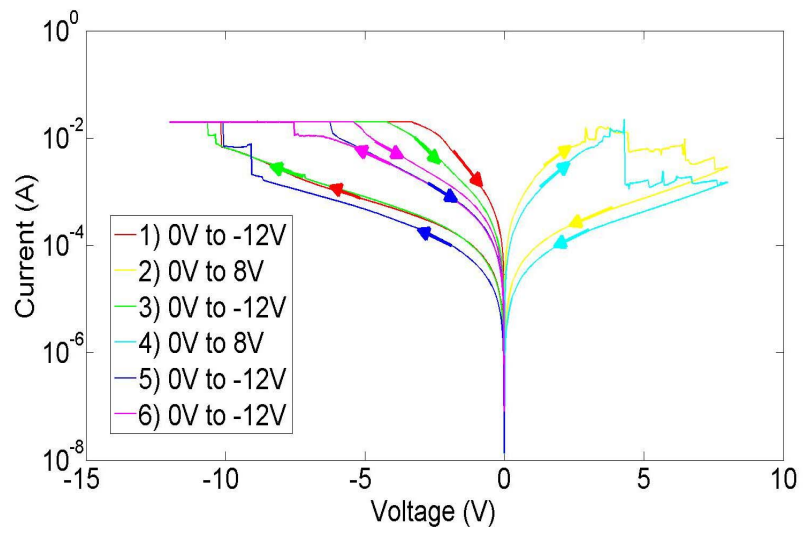

Fig. 6. IV sweeps of a $6 \mu \mathrm{m}^{2} \mathrm{HfO}_{\mathrm{x}}$ device at $350^{\circ} \mathrm{C}$ where average switching parameters are: forming voltage $=-17 \mathrm{~V}$, reset voltage $=4 \mathrm{~V}$, Ron $=2.3 \mathrm{k} \Omega$, Roff $=9.4 \mathrm{k} \Omega$, Roff $/$ Ron $=4.1$

where the first sweep is labeled as number 1 , followed by the second sweep labeled as 2 etc. The repeatability of the switching enabled a stable average Roff/Ron ratio of 13.9 to be obtained for +10 cycles (one cycle is set followed by reset). The successful repeatable switching with the large Roff/Ron ratio indicates the sub-stoichiometric $\mathrm{HfO}_{x}$ layer with lower oxygen concentration produces reliable RRAM devices.

\section{B. $H f O_{x}$ deposition at $350^{\circ} \mathrm{C}$}

Fig. 6 Shows the I-V sweeps for a $6 \mu \mathrm{m}^{2}$ sized device where the $\mathrm{HfO}_{\mathrm{x}}$ was deposited at $350^{\circ} \mathrm{C}$. The direction of the sweeps is labeled with individual arrows, where the colored arrows respond to certain sweeps as shown by the legend. The repeatability of the switching is reduced, compared to the $300^{\circ} \mathrm{C}$ device, in terms of set voltage stability, off resistance and Roff/Ron ratio. The set voltage for this device was found to decrease as measurements continued which then resulted in a reduction in off resistance, and therefore Roff/Ron ratio. The Roff/Ron ratio of this device reduces as the number of cycles increased, resulting in a lower average Roff/Ron value of 4.1, when compared to the $300^{\circ} \mathrm{C}$ devices. This reduction in ratio was also seen in $8 \mu \mathrm{m}^{2}$ sized $350^{\circ} \mathrm{C}$ devices, removing the 
possibility that the switching alterations could be due to size. The material characterization showed the $350^{\circ} \mathrm{C} \mathrm{HfO}_{\mathrm{x}}$ layer had the same crystal structure as the $300^{\circ} \mathrm{C}$ device, but with an increased oxygen concentration. This implies that the increase in deposition temperature, and therefore the increase in oxygen concentration in the $\mathrm{HfO}_{\mathrm{x}}$ layer, has reduced the switching reliability of the RRAM device.

\section{C. $H f O_{x}$ deposition at $400^{\circ} \mathrm{C}$}

No switching was observed for the device whose $\mathrm{HfO}_{\mathrm{x}}$ was deposited at $400^{\circ} \mathrm{C}$. The material characterization showed the oxygen concentration of the $350^{\circ} \mathrm{C}$ and the $400^{\circ} \mathrm{C} \mathrm{HfO}_{\mathrm{x}}$ layer were the same and therefore switching would be expected. However the XRD results show the crystal structure has altered from cubic to monoclinic $\mathrm{HfO}_{\mathrm{x}}$ and therefore it can be concluded that this structural change has caused the device switching to fail.

\section{CONCLUSION}

This work shows how the deposition temperature used for ALD of $\mathrm{HfO}_{\mathrm{x}}$ can affect the switching properties of $\mathrm{TiN} / \mathrm{HfO}_{\mathrm{x}} / \mathrm{TiN}$ RRAM devices. It is shown that when the temperature of deposition is at $400^{\circ} \mathrm{C}$, the crystal structure altered from cubic to monoclinic resulting in the inability to exhibit switching behavior. The lower temperatures show successful bipolar switching where the $300{ }^{\circ} \mathrm{C} \mathrm{HfO}_{\mathrm{x}}$ device exhibits Roff/Ron=13.9 with superior repeatability of $\mathrm{I}-\mathrm{V}$ switching compared to the $350^{\circ} \mathrm{C}$ device. The material characterization showed that the $300^{\circ} \mathrm{C} \mathrm{HfO}_{\mathrm{x}}$ has lower oxygen concentration i.e. higher concentration of oxygen vacancies; this verifies the current understanding of the switching mechanism seen in metal oxides which is thought to be related to oxygen vacancies and redox-based reactions.

\section{REFERENCES}

[1] I. G. Baek and M. S. Lee and D. H. Seo and D. -S. Suh and J. C. Park and S. O. Park and H. S. Kim and I. K. Yoo and U. -I. Chung and J. T. Moon, "Highly scalable nonvolatile resistive memory using simple binary oxide driven by asymmetric unipolar voltage pulses," in Electron Devices Meeting, IEDM Technical Digest. IEEE International, pp. 587590, December 2004

[2] R. Waser, "Resistive non-volatile memory devices," in Microelectronic Engineering, vol. 86, no.7-9, pp. 1925-1928, April 2009

[3] H. Y. Lee, P. S. Chen, T. Y. Wu, Y. S. Chen, C. C. Wang, P. J. Tzeng, C. H. Lin, F. Chen, C. H. Lien, M. -J. Tsai, "Low power and high speed bipolar switching with a thin reactive Ti bugger layer in robust $\mathrm{HfO} 2$ based RRAM," in Electron Devices Meeting. IEEE International, pp. 14, December 2008

[4] X. A. Tran, H. Y. Yu, Y. C. Yeo, L. Wu, W. J. Liu, Z. R. Wang, Z. Fang, K. L. Pey, X. W. Sun, A. Y. Du, B. Y. Nguyen, M. F. Li, "A highyield HfOx-based unipolar resistive RAM employing $\mathrm{Ni}$ electrode compatible with Si-diode selector for crossbar integration," in IEEE Electron Device Letters, vol. 32, no. 3, pp. 396-398, March 2011

[5] P. Lorenzi, R. Rao, F. Irrera, "Forming kinetics in HfO2-based RRAM cells," in IEEE Transactions of Electron Devices, vol. 60, no. 1, pp. 438443, January 2013

[6] T. Prodromakis, K. Michelakis, C. Toumazou, "Fabrication and electrical characteristics of memristors with $\mathrm{TiO} 2 / \mathrm{TiO} 2+\mathrm{x}$ active layers," in Circuits and Systems (ISCAS), Proceedings of 2010 IEEE International Symposium on, pp. 1520-1522, 2010

[7] Y. C. Bae, A. R. Lee, J. S. Kwak, H. Im, J. P. Hong, "Dependence of resistive switching behavoirs on oxygen content of the $\mathrm{Pt} / \mathrm{TiO} 2-\mathrm{x} / \mathrm{Pt}$ matrix," in Current Applied Physics, vol. 11, pp. e66-e69, February 2011

[8] I. Salaoru, T. Prodromakis, A. Khiat, C. Toumazou, "Resistive switching of oxygen enhanced TiO2 thin-film devices," in Appl. Phys. Lett. Vol. 102, no. 1, pp. 013506-1 - 013506-4, January 2013

[9] C. Cagli, J. Buckley, V. Jousseaume, T. Cabout, A. Salaun, H. Grampeix, J. F. Nodin, H. Fields, A. Persico, J. Cluzel, P. Lorenzi, L. Massari, R. Rao, F. Irrera, F. Aussenac, C. Carabasse, M. Coue, P. Calka, E. Martinez, L. Perniola, P. Blaise, Z. Fang, Y. H. Yu, G. Ghibaudo, D. Deleruyelle, M. Bocquet, C. Muller, A. Padovani, O. Pirrotta, L. Vandelli, L. Larcher, G. Reimbold, B. de Salvo, "Experimental and theoretical study of electrode effects in $\mathrm{HfO} 2$ based RRAM," in IEDM, IEEE International, pp. 28.7.1 - 28.7.4, 2011

[10] F. De Stefano, M. Houssa, V. V. Afanas'ev, J. A. Kittl, M. Jurczak, A. Stesmans, "Nature of filament formed in HfO2-based resistive random access memory," in Thin Solid Films, vol. 533, pp. 15-18, 2013

[11] S.-W. Do, Y.-H. Lee, "Study of the characteristics of HfO2/Hf films prepared by atomic layer deposition on silicon," in Journal of the Korean Physical Society, vol. 50, no.3, pp. 666-669, March 2007

[12] X. Liu, S. Ramanathan, A. Longdergan, A. Srivastava, E. Lee, T. E. Seidel, J. T. Barton, D. Pang, R. G. Gordon, "ALD from hafnium oxide thin films from tetrakis(ethylmethylamino)hafnium and ozone," in Journal of the electrochemical society, vol. 152, no. 3, pp. G213-G219, 2005

[13] S. B. S. Heil, J. L. van Hemmen, C. J. Hodson, N. Singh, J. H. Klootwijk, F. Roozeboom, M. C. M. van de Sanden, W. M. M. Kessels, "Deposition of TiN and HfO2 in a commercial 200mm remote plasma atomic layer deposition reactor," in Journal of Vacuum Science and Technology A, vol.25, no.1, pp1357, July 2007

[14] C. Hodson, N. Cing, S. Heil, H. V. Hemmen, E. Kessels, "Optimization of plasma enhanced atomic layer deposition processes for oxides, nitrides and metals in the Oxford Instruments FlexAL reactor," in the electrochemical society, vol. 3, pp. 79-86, 2007 